\title{
Generation, Distribution and Utilization of an Electrical Energy in Industrial and Domestic Buildings
}

\author{
Bhushan C. Behede, Mohammed. Juneduddin, Yogesh D. Sonawane, Dattatray S. Doifode, \\ Mahesh Dalwani
}

\begin{abstract}
If we look back few years into the past, we come to know that with the rapid development of human societies, day to day modern life and smart industries, etc. becomes so hungry and greedy for electrical energy. Today, Electrical energy is being consumed by every single machine used in almost each and every application. Conventional and nonrenewable sources like coal, oil, gas, etc. have been depleting very fast, and the world should now shift more towards renewable sources like solar, wind, tidal, etc. for harnessing electricity. Electricity consumption is increased in the industrial and domestic sectors due to the increased comfort (air conditioning) requirements, increment in the usage of power-consuming devices and the sudden increment in building occupancy area. This paper shows the current status of demand and supply scenario of electrical energy in the world and India. Generation capacities as per the renewable and nonrenewable sources in India have been discussed in detail. Almost 45\% share of the electrical energy consumed in the industrial or commercialized and domestic buildings is consumed for air conditioning purposes. the brief discussion is presented in this paper on the sales and distribution of the air conditioning units and future possibilities in the same field as per the sustainable development scenario.
\end{abstract}

Keywords:Air-conditioner, buildings, electricity, renewable energy

\section{INTRODUCTION}

India stands at the 3rd position in terms of economy and 2nd in terms of population in the world. electricity demand of such a large and diverse country is very high and it is increasing day by day. if we look at the figures then India having an $18 \%$ share in the population of the world. Electrical energy consumption in India is almost doubled from 2000 to date [1].

Revised Manuscript Received on February 05, 2020.

* Correspondence Author

Bhushan C. Behede, Assistant professor, Department of Mechanical Engineering, Shri Vile Parle Kelavani Mandal's Institute of Technology, Dhule, Maharashtra, India.

Mohammed. Juneduddin Ghulam Mohiuddin, Assistant professor, Department of Mechanical Engineering, Shri Vile Parle Kelavani Mandal's Institute of Technology, Dhule, Maharashtra, India.

Yogesh D. Sonawane, Assistant Professor, Department of Mechanical Engineering, Shri Vile Parle Kelavani Mandal's Institute of Technology, Dhule, Maharashtra, India.

Dattatray S. Doifode, Assistant professor, Department of Mechanical Engineering, Shri Vile Parle Kelavani Mandal's Institute of Technology, Dhule, Maharashtra, India.

Mahesh R. Dalwani, Assistant professor, Department of Mechanical Engineering, Shri Vile Parle Kelavani Mandal's Institute of Technology, Dhule, Maharashtra, India.

(C) The Authors. Published by Blue Eyes Intelligence Engineering and Sciences Publication (BEIESP). This is an open access article under the CC BY-NC-ND license (http://creativecommons.org/licenses/by-nc-nd/4.0/)

It has been anticipated that the commercial, industrial and civil building sector of India will reach up to $66 \%$ of the land occupancy by 2030. Every year roughly 900 million square meters of the land will be built up by the industries and domestic buildings which are like adding roughly two Mumbai cities in just one year only [2]. if no energy is conservation programs were adopted then electricity consumption in such buildings will be doubled by 2030 than it was in 2010 [3]. Electricity demand in the civil and commercial buildings sector rises by around $8 \%$ per year from 2000 to 2013. As per the International Energy Agency (IEA), almost $33.33 \%$ of global final energy is consumed by the domestic and industrial buildings and associated sectors. Also, almost $40 \%$ of total global direct and indirect $\mathrm{CO} 2$ emission is also contributed by the same sectors. Energy demand in these sectors is continuously rising and this rate is more in China and India. The possible reason behind this is the greater comfort requirements, increment in power-consuming devices, and sudden increment in building occupancy area [4]. If we talk about the energy intensity reductions in buildings then, the speed of energy intensity reductions has reduced during the last few years, roughly from $2 \%$ in 2015 to $0.6 \%$ in 2018 . Note that this is less than the floor area increase which is $2.5 \%$ between 2017 to 2018 (i.e. in one year). This decelerating and demotivating energy policy progress, clearly shows that the development of buildings and associated alike sectors are not in tune with the rapid development in growing economies. To achieve the goal of reaching the Sustainable Development Scenario (SDS), the annual reduction in energy intensity per square meter globally required to be a minimum of $2.5 \%$ [4].

In India, coal is the major source by which electricity is harnessed. almost $75 \%$ of the electricity comes with coal. Coal accounts for the largest share of electricity generation at $38 \%$ in the world. Followed by China, India is at the second position when it comes to the consumption of coal [4]. India's national coal mining company called, Coal India Limited (CIL) produces $84 \%$ coal which is the largest coal production in the world. The coal used in the power sector alone surpassed the limit of $10 \mathrm{Gt} \mathrm{CO} 2$, mostly in Asia which includes major countries like China and India. Till Nov. 2019, India had a coal reserve of 98 billion tonnes (approx.) which is roughly $9.5 \%$ of the total coal reserves of the world, Also, having overtaken the US already in 2015[5]. As of January 2019, India has 221 gigawatts of coal operating power plants. According to a global plant tracker [5], 11\% of global coal power operating power plants are in India. There is a concern in India over the health impact of coal operated power plants. 
One out of every eight deaths is reported in India due to air pollution which is mostly caused by the exhaust of coal operated plants. India is a pressure vessel with 20 most polluted cities [6]. As per the India Energy Outlook report 2015[1], India is at the third positionin the import of the cruid oil.

While the use of biomass energy (include the use of biomass for cooking and heating purpose) in the buildings has declined from 75\% in 2000 to its two-thirds in 2013[1]. This is a very alarming situation because India is largely depending on fossil fuel sources for electricity. $75 \%$ of annual energy demand in India is made by fossil fuel sources.

Now, let's focus on carbon emissions. To a very large extent, an increase in carbon emissions is the consequence of the increase in energy demand. In 2017, carbon emissions from rapid energy use grew up by $2 \%$. This number took a lead because of the faster expansion of the civil and commercial building sector. As per the analysis of CEA, in 2018, CO2 emissions all over the world increased by $1.70 \%$ to an all-time record high of 33.1 Giga-tonnes of $\mathrm{CO}_{2}$. On the other hand, $\mathrm{CO}$ emission also increased. The power sector contributed to nearly $67 \%$ of $\mathrm{CO}_{2}$ emissions growth [4]. Carbon emission increasing by an average of 0.6 gigatonnes per year. This is roughly equivalent to an increasing number of passenger cars on the planet by three times [7]. The total carbon dioxide emission of India in 2013 was 2100 million tonnes, which is almost increased by $4.4 \%$ from 2012 which makes India the fourth largest GHG (Green House Gas) emitter country, this high ranking is due to its huge population and use of fossil fuels for electricity generation [8].

All these facts and problems attracted the attention of researchers and environmental enthusiasts in developed and developing nations. In a nutshell, an overall scenario raised a challenging situation for electricity generation and its consumption in industrial, commercial and domestic buildings. This paper highlights the current demand, production and supply scenario of electrical energy in the world and India. through this paper, authors have tried to bring some light on the consumption of high-grade energy produced by using renewable sources. This paper briefly explains the electrical energy utilization in industrial, commercial and domestic buildings with the focus on the consumption of electricity for the purpose of air conditioning. Sales and distribution of air conditioning units have been reviewed and future possibilities in an Indian market are anticipated.

\section{METHODOLOGY}

Table 1: steps of detail study
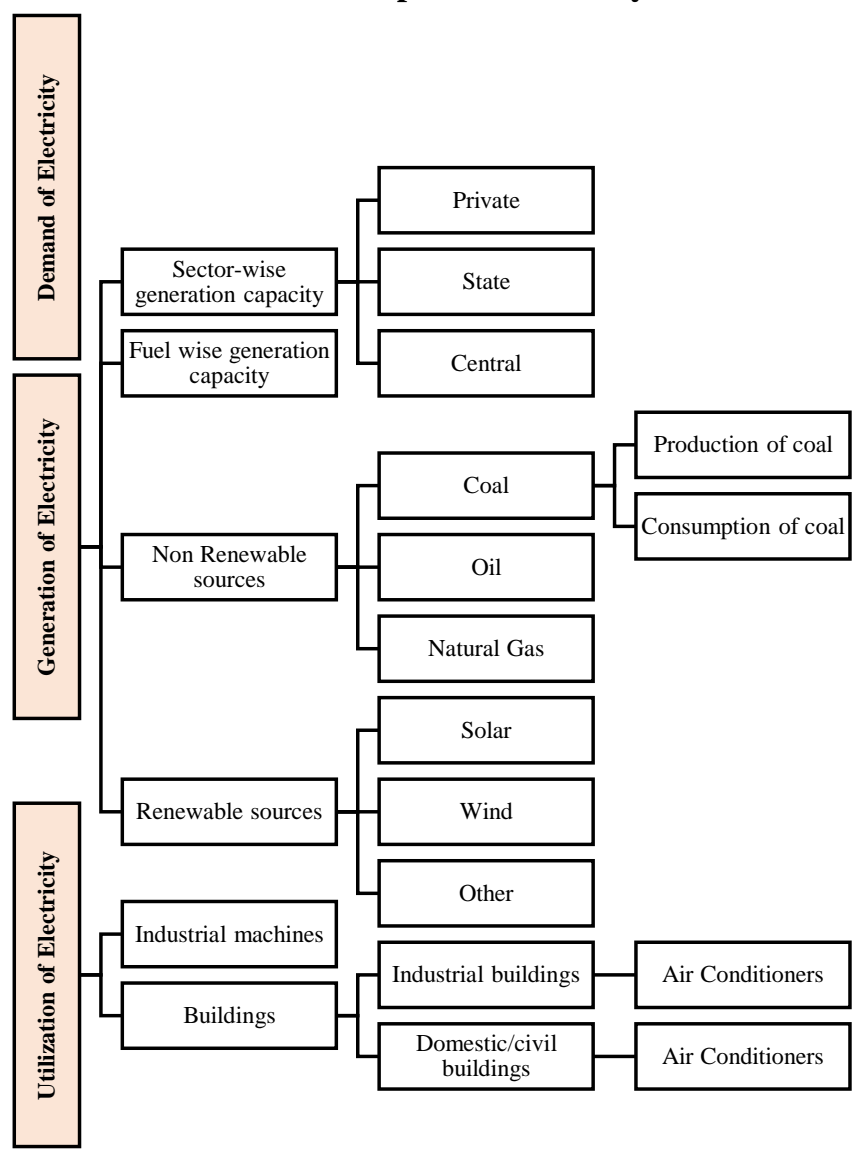

\section{BACKGROUND}

\section{A. Overview of Electrical power sector in India}

India is the seventh-largest country by area and second by population on the earth. To fulfill the electricity demand of such a large developing nation is very difficult. The electricity sector of India is mainly divided into three sectors, namely, Central, state and private. The central sector of electricity generation is controlled by the central government while some of the freedom is given in the state sector and private sector regarding the production and sale of the electricity generated in these sectors. Let's look at the Generation capacities of these sectors in Megawatts (MW) is shown in Table 2. The private sector is the largest contributing around $47 \%$ in the electricity generation followed by the state sector and the central sector contributing 28\% and 25\% respectively as shown in Figure 1.

Table 2: Total Electricity Generation Capacity of India up to 30 Nov. 2019 [9]

\begin{tabular}{|c|c|}
\hline Sector & MW \\
\hline Central Sector & 91496.93 \\
\hline State Sector & 103815.14 \\
\hline Private Sector & 170668.47 \\
\hline Total & 365980.54 \\
\hline
\end{tabular}

Published By: 
Electricity Generation Capacity of India sector wise distribution (\%)

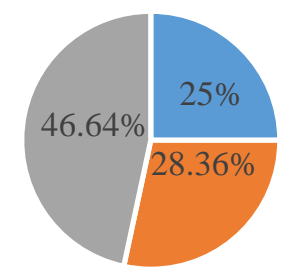

- Central Sector $\quad$ State Sector $\quad$ Private Sector

Figure 1: Sector-wise distribution of installed power capacity in India

\section{B. Sector-wise distribution of Electricity Generation Capacity of India}

Now, combining all the sectors providing electricity to every house and building in the country $24 * 7$ but, still, the demand is more than the production. Before studying the demand and supply scenario of electricity, let's take a look at the generation of electricity by different sources as shown in Error! Reference source not found.. Coal, diesel, gas, etc. sources come under Thermal sources which are the major contributing sources in the generation of electricity. Thermal sector producing 2,29,401 MW of electricity alone and contributing around $63 \%$ in the generation of electricity as shown in Error! Reference source not found.. Renewable sources like solar, wind, tidal, geothermal, etc. are contributing $23 \%$ followed by $13 \%$ of hydropower and $1 \%$ of nuclear energy. As per the breakdown of thermal sources, Coal is the major source and mainly used for electricity generation in India.

Table 3: Breakdown of Electricity Generation Capacity of India up to 30 Nov. 2019 [9]

\begin{tabular}{|c|c|}
\hline Type of Fuel (Energy source) & Generation in MW \\
\hline Gas & 24937 \\
\hline Lignite & 6260 \\
\hline Coal & 197695 \\
\hline Diesel & 510 \\
\hline Total Thermal & 229401 \\
\hline Hydro (Renewable) & 45399 \\
\hline RES* (MNRE) & 84400 \\
\hline Nuclear & 6780 \\
\hline Total generation & 365981 \\
\hline
\end{tabular}

*Electricity generation in respect of Renewable Energy Sources (RES) and Ministry of New and Renewable Energy (MNRE) as on date 30 Nov. 2019. RES include Small Hydro Project, Biomass Gasifier, Biomass Power, Urban \& Industrial Waste Power, Solar, and Wind Energy.

\section{Fuel wise breakdown of installed capacity of India.}

Breakdown of Electricity generation capacity India - mode of generation wise (\%)

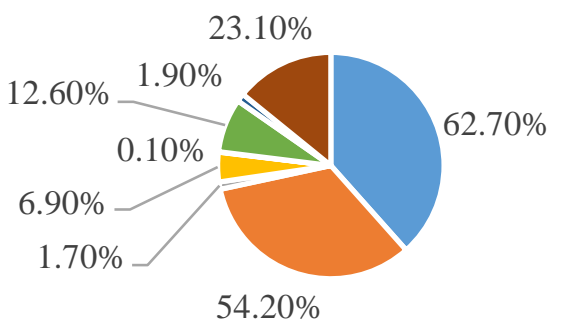

$$
\begin{array}{ll}
\text { - Total Thermal } & \text { - Coal } \\
\text { - Lignite } & \quad \text { Gas } \\
\text { - Diesel } & \text { - Hydro (Renewable) } \\
\text { - Nuclear } & \text { - RES* (MNRE) }
\end{array}
$$

Figure 2: Fuel wise breakdown of installed capacity of India.

\section{RESULTS AND DISCUSSIONS}

Electricity is the basic need of Industrialization. Take a look at electricity production in India from 2008 to 2018. As shown in Figure 3, Electricity generation in India is boosted continuously from 2008 to 2018. India is the developing nation and as being the one electricity should reach to every corner of India.

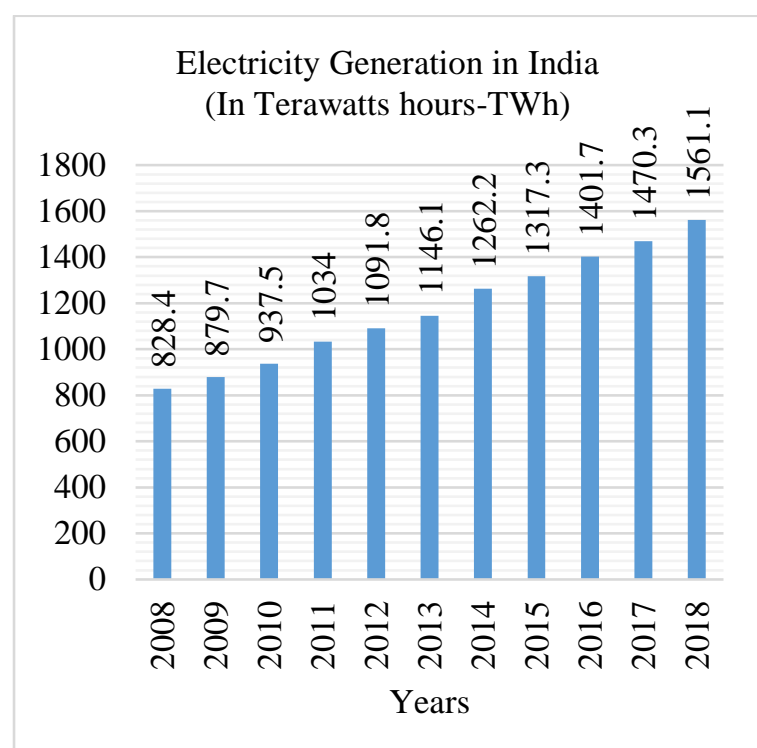

Figure 3: Electricity Generation in India(In Terawatts hours) from 2008 to 2018.

The energy extracted directly from the natural resources is called as primary energy. If energy is drawn from the depleting resource like fossil fuels then it is called the nonrenewable source of primary energy and if the energy is derived from the non-depleting resources like hydro, solar, wind, waves, etc. then it is called as a renewable source of primary energy. Take a look at the primary energy consumption in India as indicated in Figure 4. 


\section{Genertion, Distribution and Utilization of an Electrical Energy in Industrial and Domestic Buildings}

Consumption of Primary energy in India is increased from 478 million tonnes of oil equivalent (mtoe) in 2008 to around 810 mtoe in 2018. This increase shows that now India is equipped with good electricity harnessing technology. Now take a look at the numbers of primary energy consumption by fuel in 2017 shown in Figure 5. Coal is still being a major source of electricity production in India which is $55.4 \%$ of remaining other fuels. This percentage is slightly increased in 2018 as shown in Figure 6, but not decreased which is supposed to. Coal, oil, etc. are responsible for the problem of global warming and $\mathrm{CO}_{2}$ emission around the globe. Share of other major sources can be easily understood from Figure 5 and Figure 6. As a step towards sustainable development, India should look for renewable energy sources and at the same time, the percentage of coal consumption also should be decreased.

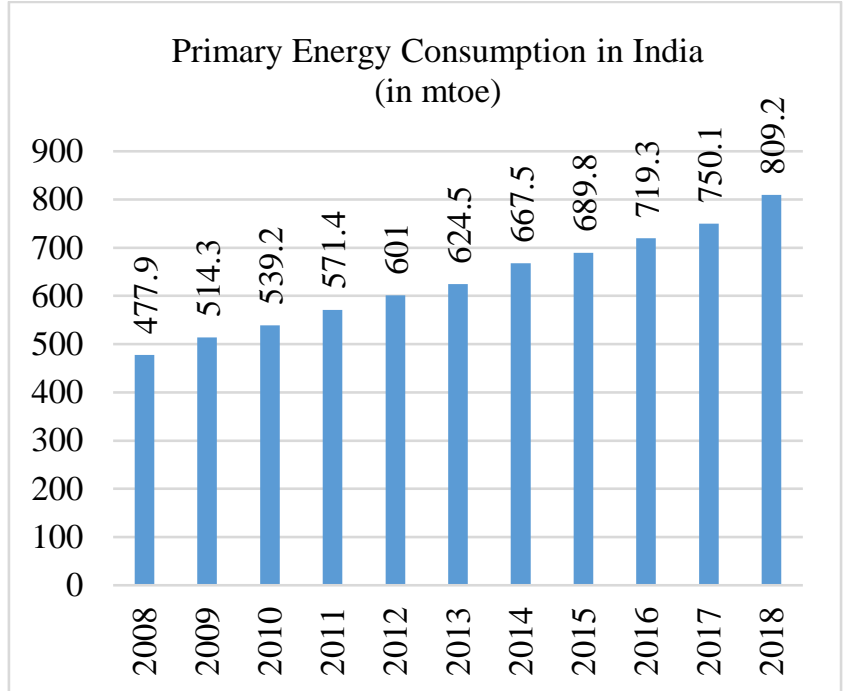

Figure 4: Consumption of Primary Energy in India (in mtoe) from 2008 to 2018 [7]

Consumption of Primary Energy by Fuel in India 2017 (in \%)

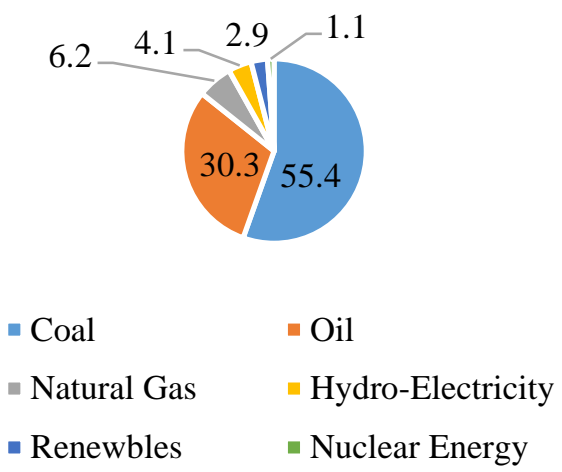

Figure 5: Consumption of Primary Energy as per Fuel in India - 2017 (in \%)[7]

Consumption of Primary Energy by Fuel in India 2018 (in \%)

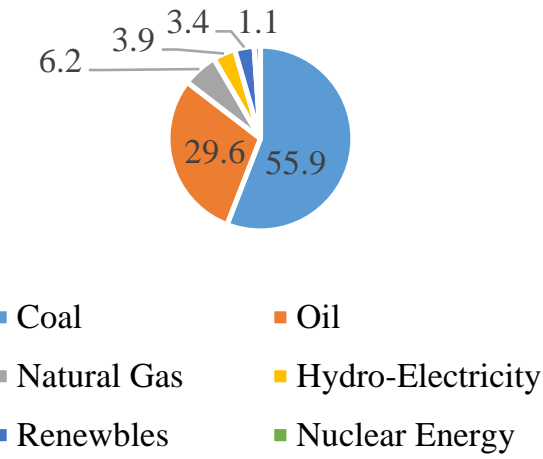

Figure 6: Consumption of Primary Energy as per Fuel in India - 2018 (in \%)[7]

Coal is the major central element of electricity production in India. Let's look at coal production in India in terms of the million tonnes of oil equivalent. As shown in Figure 7, the coal production scenario in India from 2008 to 2018 is not so pleasing enough. No doubt new coal sources have been found out and coal production is increased but the major hike is still missing. On the other hand, coal consumption figures in India from 2008 to 2018 are available in Table 4: coal consumption in India (in mtoe) from 2008 to 2018, which shows the continuous rise. Even the renewable energy policy of an India is seems to be impressivebecause of the names like National Action Policy on Climate Change (NAPCC) and the National Solar Mission (NSM) but still, according to authors coal consumption in India should take a declined curve as it is the increasing year by year as shown in Figure 8.

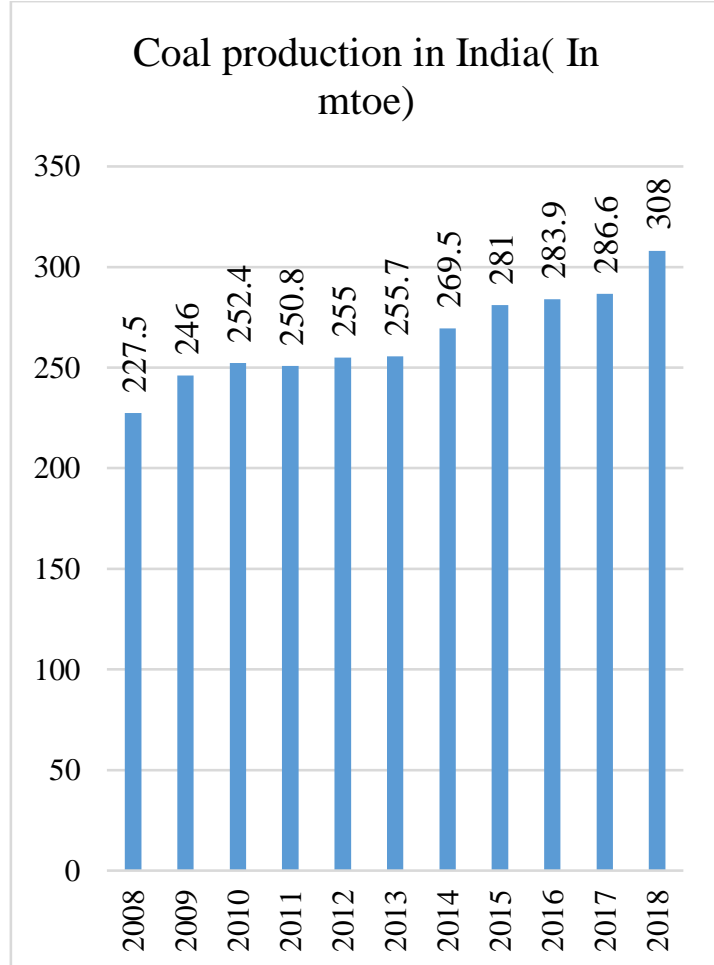

Figure 7: Coal production in India( In mtoe) from 2008 to 2018 [7] 
Table 4: coal consumption in India (in mtoe) from 2008 to 2018

\begin{tabular}{|c|c|}
\hline Year & Coal Consumption in India( In mtoe) \\
\hline 2008 & 259.3 \\
\hline 2009 & 280.8 \\
\hline 2010 & 290.4 \\
\hline 2011 & 304.6 \\
\hline 2012 & 330 \\
\hline 2013 & 352.8 \\
\hline 2014 & 387.5 \\
\hline 2015 & 395.3 \\
\hline 2016 & 400.4 \\
\hline 2017 & 415.9 \\
\hline 2018 & 452.2 \\
\hline
\end{tabular}

Coal Consumption in India( In mtoe)

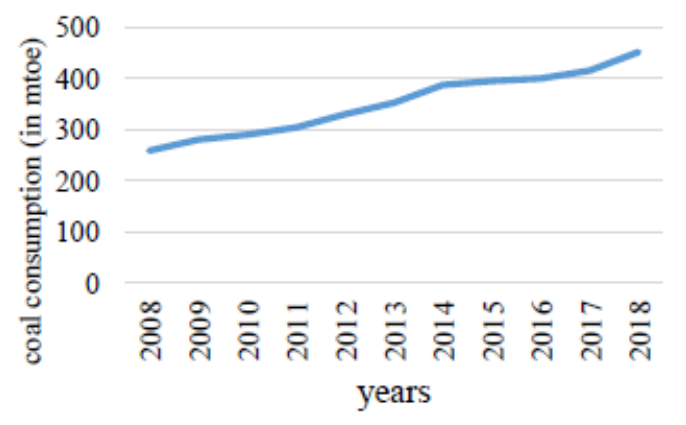

Figure 8: Coal consumption in India (in mtoe) from 2008 to 2018.

Electricity generation by renewable sources has been increased in 2018 compared to 2017 as shown in Figure 9. Wind energy, solar energy being the most popular source in India, harnessing electricity which is called clean or green sources of high-grade energy. Solar energy is the most focused by researchers and many government policies are available in India to adopt solar energy. Still, solar energy has never been the most popular source of renewable energy in India. As per the analysis was done by Komali et al. [10], the non-bankability of projects, Lack of uniform government policy, and lack of access to domestic content availability are the major challenges in front of India to take solar mission upfront.

Electricity Generation by Renewable Sources in India 2017 and 2018 (Terawatts hours)

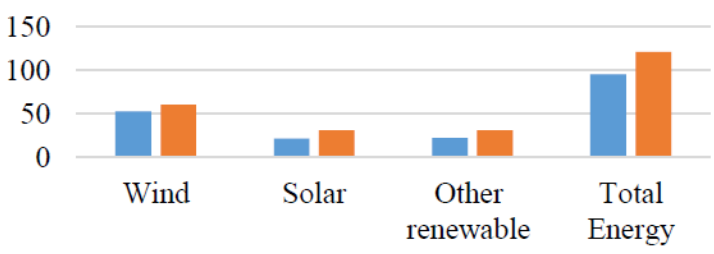

Generation (Terawatts hours)-2017

- Generation(Terawatts hours)-2018

Figure 9: Electricity Generation by Renewable Sources in India 2017 and 2018 (Terawatts hours)[7]

If we see the trend of electricity consumption, then we can say one thing for sure that electricity consumption has been increased in India. Now the question is what is the \% rate by which this consumption is increased and why. According to the report by CEA[11], Govt. of India, electricity consumption has been increased by $7.82 \%$ from 2008 to 2017. Whereas, after 2017, electricity consumption was increased by $6.5 \%$ in just one year. This increase in electricity consumption is notorious. According to the same report, the share in electricity consumption is more of the Industrial sector. i.e. around $40 \%$ of the total. After the industrial sector, the domestic sector accounted for $25 \%$ followed by agriculture and the commercial sectors accounted for $19 \%$ and $9 \%$ respectively[11]. This shows that electricity consumption is increased at a faster rate in the industrial and domestic sectors of India. The growth rate in the industrial sector is $8.46 \%$ in the industrial sector and $7.93 \%$ in the domestic sector. As per the reports of CEA[11] and IEA[4], the Reasons behind this increase are the greater comfort requirements, increment in the use of power-consuming devices, and sudden increment in buildings occupancy area. To fulfill the comfort requirements in the industrial and civil buildings, air conditioners and allied technologies are most popular. Air conditioners and allied technologies are running on the Vapor Compression Refrigeration System (VCRS). VCRS technology consume high-grade energy i.e. Electrical energy in a large amount. This is the key indicator that the electrical energy consumption is increased in the industrial and civil buildings by a notorious amount.

Air conditioning is the science which deals with the operations on air to control its temperature, humidity, quality, and purity. Air conditioners are supposed to handle all these tasks simultaneously. Air conditioners run on the VCRS system. A reciprocating (in many units) or rotary (in some units) Compressor is the heart of the VCRS system and refrigerant flowing in the system can be referred to as blood[12]. Air conditioning is the most important need in the industrial and civil buildings and in related sectors. The demand of electricity all over the world is increased by 3 folds between 1990 to 2018 by roughly 2000 terawatt-hours (TWh). 5\% more energy used for space cooling globally in 2018 as compared to 2017 because 2018 was the hottest year in many regions across the globe. Currently, around 1.6 billion air conditioner units are in operation around the world. AC sales go up worldwide, an estimated 15\% between 2017 and 2018 and hence this sector became an emerging economy in 2018. No doubt, China is the leading in the world in the sales and use of air conditioner units[4]. As per the analysis was done by IEA, one in a three air conditioner unit has been sold in China. More than 350 million units are in operation alone in china in 2017 and this number is again rose up in summer 2018. Other developing economies like Brazil, India, Mexico, and Indonesia together represented a sale of nearly 100 million Air Conditioner units in 2018 back to china[4]. As per the analysis was done by the Indian Society of Heating Refrigerating and Air Conditioning Engineers(ISHRAE) is 2015, the market of air conditioners units (of all types) has been increased by around annual compound growth rate of $20 \%$ in last 10 years. The market took a lead from 3.8 million units in operation in 2013 to about 4 million in operation in 2014[13].

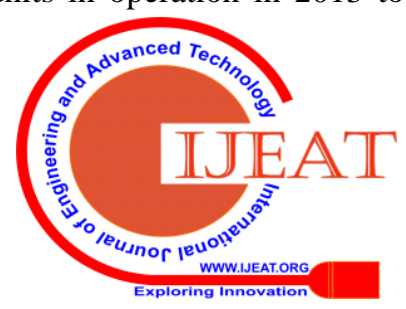


Figure 10 shows the adaptability scenario of air conditioner units in the selected countries where the market for air conditioning is at a peak. Japan is the country where $91 \%$ of houses are equipped with air conditioning units. Companies are earning a lot of revenue in Japan as maintenance and replacement (in few cases) services are need to be provided. Only 5\% of houses in India are equipped with air conditioners. this shows that there is a lot of scopes for air conditioning companies to sell as many units as possible. If companies provide state of the art technology at affordable prices, then the population will start accepting air conditioning units rapidly. After this automatically maintenance services will be required so the companies can earn revenues up to the long term.

$\%$ age of household equipped with Air Conditioner Units in selected countries 2018.

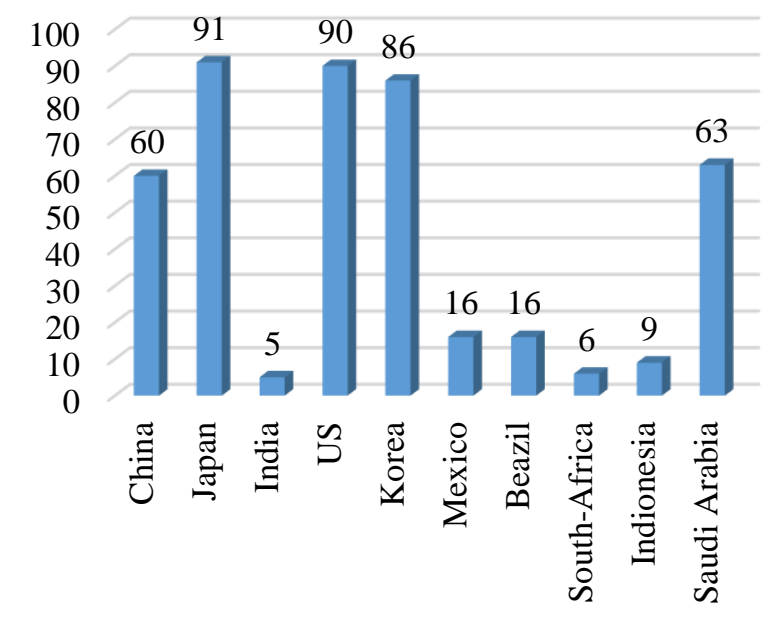

Figure 10: \%age of household equipped with Air Conditioner Units in selected countries 2018[7]

An increasing number of air conditioners is directly or indirectly impacting the power generation \& distribution facility. especially, during peak demand periods and extreme summer season. Peak load demand on the power generation facility increases directly up to $50 \%$ by space cooling and conditioning requirements alone. $\mathrm{CO}_{2}$ emissions problem because of the space cooling is also increasing rapidly. Examining data between 1990 and 2018, almost 1130 million tonnes of $\mathrm{CO}_{2}$ is emitted worldwide. Due to higher demand in cooling load, Local air pollutant emissions also goes on the rise. Higher-efficiency air conditioners are currently available in the market however, most of the people of India prefer to buy new air conditioning units that are two to three times less efficient. To achieve the goal of SDS, the Indian market should adopt standards so that the performance of AC's should increase more than $50 \%$ by the year 2030 . This will cut down electricity consumption and $\mathrm{CO}_{2}$ emissions. Also, it will limit the peak electricity demand. Positively, the average Seasonal Energy Efficiency Ratio (SEER) of air conditioner units installed worldwide increased from 3.5 in 2010 to around 4.1 in late 2018, still, data from product registries shows that this number is still far below the index of performance of more efficient options available in the market. Average SEER of Air Conditioner units sold in the markets, such as China and India, is typically below 3.5 but products available in these markets are often at comparable prices can have SEER's that are $50 \%-70 \%$ better. It has been anticipated that, without any improvements in the performance of cooling equipment, the need for electricity for cooling in buildings could be increased by up to $65 \%$ globally by the year 2030 . It is $45 \%$ higher than the limit as per SDS. To achieve the goal of SDS, the average efficiency of new AC units should be SEER of 7 (which is 4.1 today). To achieve this target is difficult and it would require strong market signals and greater inter-country corporation.

The adoption of renewable cooling technologies has been already started in 2005, and the fastest-growing energy sector is solar energy which can be also utilized in cooling technology. But, Solar energy in cooling technologies is still less popular in the global market, with less than 2000 units deployed worldwide up to 2018 have initiated an awareness in the global market. The sales and distributions are increasing worldwide after Solar Air Conditioner units were started commercialized in 2018. The solar thermal cooling system typically combines heat-driven chillers working either on absorption or adsorption phenomenon, desiccant based evaporative cooling and dehumidification systems, solar thermal collectors and thermal storage systems. With such state of the art technologies, users can operate the Air Conditioner units with renewable and low-grade energy to set the cooling output according to the electricity. Governments can reduce the increasing electricity demand by supporting green building technologies such as solar cooling systems. With all these discussions we can come to the conclusion that the adoption of renewable energy is the need of the future. It is the best possible way towards the sustainable development scenario.

\section{CONCLUSION}

India mostly dependent on conventional nonrenewable sources like coal, oil, gas, etc. for power generation. In the view of achieving sustainable development, India should shift more dependency on renewable sources like solar, wind, tidal, etc.Indian governments, funding agencies should support Researchers to initiate the Research and Development efforts to increase the use of innovative Air Conditioning technologies that use refrigerants with low global-warming potential (GWP) and Ozone Depletion Potential (ODP).

Governing bodies should promote innovative business models that encourage the use of digital technologies such as smart control strategies, thermostats and other improved techniques that optimize the effective load distribution of electricity demand for cooling. Governing bodies should also support industries to manufacture smarter and more sustainable Air Conditioner units.

There is a huge market is available in India for the sales and distribution of air conditioning units as only $5 \%$ of houses in India are equipped with air conditioners. The solar cooling systems with solid and liquid desiccant material could reduce cooling demand notably because they consume very less amount of high-grade energy for their operation compared to conventional Vapor Compression Refrigeration (VCR) Units. 
Today's consumers are not purchasing air conditioner units which are efficient enough. The efficiency of the majority of air conditioner units sold in the market today is less than one-third of the best available cooling technology which is available in the market.

\section{REFERENCES}

1. India energy outlook report (IEA), "India Energy Outlook," World Energy Outlook Spec. Rep., pp. 1-191, 2015.

2. S. Sankhe et al., "India 's urban awakening : Building inclusive cities, sustaining economic growth," McKinsey Q., no. April, pp. 1-33, 2010.

3. K. Pantong, S. Chirarattananon, and P. Chaiwiwatworakul, "Development of energy conservation programs for commercial buildings based on assessed energy saving potentials," Energy Procedia, vol. 9, pp. 70-83, 2011.

4. IEA (2019), “"Tracking Buildings.” [Online]. Available: https://www.iea.org/reports/tracking-buildings.

5. C. I. Limited, "Annual Report and Accounts."

6. K. Balakrishnan et al., "The impact of air pollution on deaths, disease burden, and life expectancy across the states of India: the Global Burden of Disease Study 2017," Lancet Planet. Heal., vol. 3, no. 1, pp. e26-e39, 2019.

7. British Petroleum, "BP Statistical Review of World Energy 2019|68th Edition," 2019.

8. H. Maheshwari and K. Jain, "Trends of Energy Consumption and Carbon Footprint in India," Int. J. Appl. Environ. Sci., vol. 12, no. 3, pp. 457-468, 2017.

9. Government of India, "All India Installed Capacity ( in Mw ) of Power Stations Installed Capacity ( in Mw ) of Power Utilities in the States / Uts Located in," Cent. Electricity Authority, Ministry. power, vol. 4, pp. 1-7, 2018.

10. K. Yenneti, "The grid-connected solar energy in India: Structures and challenges," Energy Strategy. Rev., vol. 11-12, pp. 41-51, Jun. 2016.

11. Central Electricity Authority, "Growth of Electricity sector in India from 1947-2019."

12. G. F. Hundy, A. R. Trott, and T. C. Welch, "Chapter 1 Fundamentals," in Refrigeration and Air-Conditioning (Fourth Edition), Fourth Edi., G. F. Hundy, A. R. Trott, and T. C. Welch, Eds. Oxford: Butterworth-Heinemann, 2008, pp. 1-14.

13. ISHRAE, "Air Conditioner Market in India," 2015. [Online]. Available:

https://ishrae.in/newsdetails/Air-Conditioner-Market-in-India/338.

\section{AUTHORS PROFILE}

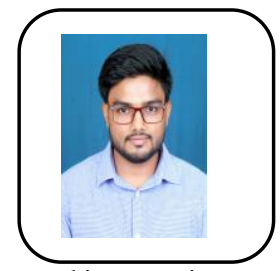

Bhushan C. Behede, completed M. Tech. in the Heat power engineering during 2014-16. He was awarded the silver medal for being a topper in the department. Currently, He is working as an Assistant professor in the Department of Mechanical Engineering at Shri Vile Parle Kelavani Mandal's Institute of Technology, Dhule, Maharashtra, India. He has more than 3 years of teaching experience and 2 years of research experience. He is a professional life member of the International Association of Engineers (IAENG) and an associate member of the Universal Association of Mechanical and Aeronautical Engineers (there). He has published 4 papers in various journals, presented 4 papers in various conferences and 1 book chapter. His research areas are Sorption refrigeration systems, Adsorption Cooling System (ADCS), Finned tube type heat exchanger, Chemical Dehumidification, Desiccants and their use in Dehumidification, Natural refrigerants, and their uses.

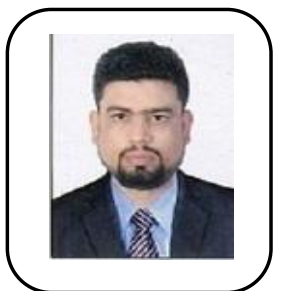

Mohammed. Juneduddin Ghulam Mohiuddin, completed M. Tech. in the Heat Power Engineering during 2007-2009 from Visvesvaraya National Institute of Technology (VNIT), Nagpur. Currently, he is working as an Assistant professor in the Department of Mechanical Engineering at Shri Vile Parle Kelavani Mandal's Institute of Technology, Dhule, Maharashtra, India. He has more than 9 years of teaching experience and 4 years of research experience. His research areas includecomputational fluid dynamics, heat transfer, thermodynamics, refrigeration systems, computer aided design and manufacturing, etc.

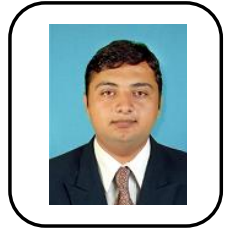

Yogesh D. Sonawane, completed M. Tech. in the Mechanical Engineering during 2010-12. Currently, $\mathrm{He}$ is working as an Assistant Professor in the Department of Mechanical Engineering at Shri Vile Parle Kelavani Mandal's Institute of Technology, Dhule, Maharashtra, India. He has more than 7 years of teaching experience, 2 years of industrial experience and 2 years of research experience. He is a life time member of Indian Society for Technical Education (ISTE), professional life member of the International Association of Engineers (IAENG) and an associate member of the Universal Association of Mechanical and Aeronautical Engineers (theIRED). He has published 3 papers in various journals and presented 2 papers in various conferences. His research areas are IC engine, Automobile Engineering, Vehicle Integration and Thermodynamics

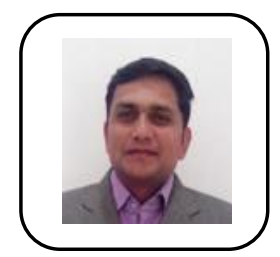

Dattatray S. Doifode, completed M.E. in Heat Power Engineering in April 2014. He has a more than 10 years of teaching experience in reputed institutes and universities in Maharashtra State. Currently, He is working as an Assistant professor in the Department of Mechanical Engineering at Shri Vile Parle Kelavani Mandal's Institute of Technology, Dhule, Maharashtra, India. He has presented 1 paper in national conference. His research areas are natural convection enhancement by using different geometries of fin, perforations, orientations, and various other techniques, performance analysis of I.C. Engines, use of renewal fuels.

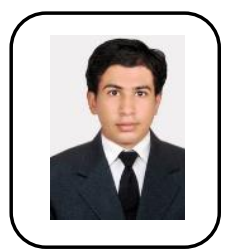

Mahesh R. Dalwani, completed M. Tech. in Thermal Engineering. He has a more than 2 years of teaching experience. Currently, He is working as an Assistant professor in the Department of Mechanical Engineering at Shri Vile Parle Kelavani Mandal's Institute of Technology, Dhule, Maharashtra, India. He has presented 2 paper in the International Conferences and 2 Papers in the International journals. His research areas are heat transfer, I. C. Engines and energy and environmental engineering. 